\title{
EDITORIAL
}

\section{Asthma action plans in action; nurses' roles in promoting self-management}

See paper by Cleland et al on page 311 and paper by

Blake et al on page 319

Asthma remains a significant cause of morbidity and mortality despite the availability of effective treatments. Successful asthma control is likely to depend on clinicians prescribing appropriate treatment in line with evidence-based guidelines ${ }^{1}$ and then patients taking this treatment in therapeutic doses. Adherence to treatment may be aided by a self-management plan. ${ }^{2}$ However, adherence to guidelines and adherence to treatment depend on the knowledge and behaviour of the clinicians involved.

In this issue of the Primary Care Respiratory Journal (PCRJ), Cleland et al report their findings from a cluster randomised controlled trial measuring the impact of a short educational intervention - delivered to practice nurses - on asthma outcomes in patients with poorly controlled asthma. ${ }^{3}$ This was a feasibility study, in that it aimed to identify practical and methodological issues to inform the design " and implementation of a larger cluster randomised controlled trial. The findings were disappointing, showing little impact of the three-hour educational intervention on asthma outcomes. With commendable honesty and clarity, the authors describe the difficulties they encountered, concluding that evaluations of educational interventions are complex both in terms of their design and their delivery. Despite this, the study makes an important contribution to the scientific literature in that it recognises the importance of educational interventions and attempts to measure the impact of such an intervention in a 'real life' primary care population.

One of the difficulties with trying to assess the impact of training for healthcare professionals is that its role in managing patients is unclear. Changes in health outcomes may occur as a result of direct exposure to healthcare professional education via alternative forms of health information rather than information from, say, the practice nurse. Furthermore, being able to reduce symptoms and improve quality of life is likely to depend on many patientrelated factors, including patients' knowledge of their disease, the appropriateness and effectiveness of treatment, patients' compliance with treatment, and regular follow-up.
Nevertheless, it is increasingly recognised ${ }^{4}$ that appropriately powered, well-constructed trials are needed to establish the role of education and training in improving both the knowledge and behaviour of health professionals and the health status of their patients.

Cleland et al report a number of methodological limitations, ${ }^{3}$ many of them driven by practical considerations and a desire to minimise the time and effort required by the practice nurse participants. In spite of this, however, the study provides useful information and highlights a number of important points to be considered when designing evaluations of complex educational interventions in primary care:

1. An understanding of the barriers to health professional participation in research studies is vital to enable effective recruitment and retention of participants. Ethical incentives tô participation need to be carefully considered and, if financial, included in the study budget.

2. Outcome measures require careful consideration and, in an evaluation of an educational intervention, could include: consultation rates; prescriptions; investigations; referrals; symptoms; quality of life; adherence to treatment; and knowledge.

3. Measurement of the impact of training on professional knowledge, confidence, competence and behaviour is necessary to understand and interpret any impact on patient outcomes.

4. Knowledge of the importance of the content, format and duration of training programmes can be used to design interventions which have the best chance of changing clinician behaviour.

5. Greater emphasis needs to be placed on routine data entry and coding in general practice to enable data to be collected with minimum time and effort.

In a recent editorial in this journal, ${ }^{5}$ Monica Fletcher highlighted the need for evidence-based educational programmes which can support the implementation of the government-led National Service Frameworks for the management of chronic diseases, and the delivery of high quality patient care. Information from the study by Cleland et $\mathrm{al}^{3}$ thus provides a useful source of information for researchers in this field. 
In another interesting paper in this month's PCRJ, Partridge and colleagues investigated the roles and responsibilities of nurses delivering respiratory care in general practice. ${ }^{6}$ Practice nurses appear to be the principal providers of chronic respiratory disease management in primary care, with asthma and chronic obstructive pulmonary disease (COPD) accounting for $93 \%$ of their respiratory consultations. Although findings from this small study reveal that nurse participants felt they had sufficient training to deliver the level of respiratory care they currently provided, with further training (particularly in advanced asthma management and basic (OPD) their roles could be extended to provide an even better service to patients. This training should be constructed and delivered in a format that is most likely to change clinicians' behaviour, therefore justifying the financial and intellectual investment involved.

In summary, optimal respiratory care depends on clinicians having the knowledge and skills both to prescribe the appropriate treatment and to build a successful patient partnership that ensures that treatment is taken at therapeutic doses. Educational interventions involving sustained study and regular self-assessment over six months have been shown to improve professional and patient outcomes, ${ }^{7}$ but further well-constructed studies in different disease areas are needed to confirm the importance of education and training in delivering high quality respiratory care in primary care.

\section{References}

1. British Thoracic Society (BTS), Scottish Intercollegiate Guidelines Network. British guideline on the management of asthma. Revised ed. http://www.sign.ac.uk/guidelines/fulltext/63/index.html . 20-4-2004. SIGN.

2. Gibson PG, Coughlan J, Wilson AJ, et al. Self-management education and regular practitioner review for adults with asthma. Cochrane Database Syst Rev CD001117. 2003.

3. Cleland JA, Hall S, Price D, Lee AJ. An exploratory, pragmatic, cluster randomised trial of practice nurse training in the use of asthma action plans. Prim Care Resp J 2007;16(5):311-18. doi:10.3132/pcrj.2007.00063

4. Todres M, Stephenson A, Jones R. Medical education research remains the poor relation. BMJ 2007;335:333-5.

5. Fletcher M. Continuing education for healthcare professionals: time to prove its worth. Prim Care Resp J 2007;16(3):188-90. doi:10.3132/pcrj.2007.00041

6. Blake D, Roberts NJ, Partridge MR. How much of a primary care nurse's time is spent on those with respiratory disease? A pilot study. Prim Care Resp J 2007;16(5):319-20. doi:10.3132/pcrj.2007.00061

7. Sheikh A, Khan-Wasti S, Price D, Smeeth L, Fletcher M, Walker S. Standardized training for healthcare professionals and its impact on patients with perennial rhinitis: a multi-centre randomized controlled trial. Clin Exp Allergy 2007; 37:90-9.

\section{*Samantha Walker}

Director of Education and Research, Education for Health,

The Athenaeum, 10 Church Street, Warwick, CV34 4AB, UK

${ }^{*}$ Correspondence:

Tel: +44 (0)1926 838975

Fax: +44 (0)1926 493224

E-mail: s.walker@educationforhealth.org.uk

11 th September 2007

\section{Available online at http://www.thepaj.org}

